\title{
Study on combustible gas generation and radionuclide release during underwater handling of the $A M$ reactor spent fuel*
}

\author{
Artyom Z. Gayazov ${ }^{1}$, Anton Yu. Leshchenko ${ }^{1}$, Valery P. Smirnov ${ }^{1}$, Pavel A. Ilyin ${ }^{2}$, Vadim G. Teplov ${ }^{2}$ \\ 1 SOSNY R\&D Co. Ltd., 4 a Dimitrov Ave, 433507 Dimitrovgrad, Ulyanovsk Reg., Russia \\ 2 JSC SSC RIAR, 9 Zapadnoye Shosse, 433510 Dimitrovgrad, Ulyanovsk Reg., Russia \\ Corresponding author: Artyom Z. Gayazov (gaz@sosny.ru)
}

Academic editor: Yury Kazansky • Received 19 December 2020 Accepted 13 May 2021 • Published 23 September 2021

Citation: Gayazov AZ, Leshchenko AYu, Smirnov VP, Ilyin PA, Teplov VG (2021) Study on combustible gas generation and radionuclide release during underwater handling of the AM reactor spent fuel. Nuclear Energy and Technology 7(3): $223-229$. https://doi.org/10.3897/nucet.7.73491

\begin{abstract}
Introduction. The paper addresses studies on the accumulation of combustible gases during underwater handling simulations for the leaky spent nuclear fuel from the AM reactor. Two fuel compositions were studied- uranium-molybdenum dispersed in magnesium and uranium carbide dispersed in calcium.

Methods. The ${ }^{137} \mathrm{Cs}$ release rate was measured during underwater storage of the uranium-molybdenum fuel. The kinetics of hydrogen release for both fuels and methane release for the carbide SNF were obtained. The kinetics approximate most with exponential dependences that formally correspond to first-order chemical reactions.

A contribution of radiolytic hydrogen to the gases generated during the experiments was estimated. It was demonstrated that the determining source of the gases is the chemical interaction between the spent fuel and the water.

The experiment with the uranium-molybdenum fuel demonstrated a pronounced passivation effect of the chemical processes on the fuel surface due to insoluble corrosion products. For the carbide SNF, an incubation period of about 20 hours was observed followed by an intensive release of hydrogen and methane.

Results. The obtained results were subject to a comparative analysis against publications on the behavior of the fuel components in water.

Conclusion. The findings can be applied to justify fire and explosion safety of underwater handling techniques for the damaged spent nuclear fuel with the considered fuel compositions (the spent fuel from reactors AM, AMB, EGP-6, etc.), e.g., to justify underwater preparations of the AMB spent fuel for reprocessing.
\end{abstract}

\section{Keywords}

Fire and explosion safety, damaged SNF, AM (AMB) reactor, radiolysis, hydrogen, methane, underwater storage

* Russian text published: Izvestiya vuzov. Yadernaya Energetika (ISSN 0204-3327), 2021, n. 2, pp. 71-82. 


\section{Introduction}

Safe underwater handling of the spent nuclear fuel and radioactive waste throughout the entire nuclear fuel cycle requires justifying the fire and explosion safety of the techniques used. The combustible gases accumulate in the equipment either as a result of the water radiolysis or the chemical reactions during handling of the leaky spent fuel.

In general, the generation rate for combustible gases depends on many reasons, such as the nature and concentrations of substances, pressure, temperature, the presence and concentrations of catalysts and impurities, the SNF damage, the equipment geometry, and the radiation dose rate. But even a simple case of the VVER spent fuel oxides gives us no chance to analytically take into account the effect of all components on the hydrogen generation (Gayazov et al. 2018). It is even more the case when describing the release of combustible gases and radionuclides from the multicomponent spent fuel, such as the spent fuel fragments from the AMB reactor ("Large Peaceful Atom"; Russian: Атом Мирный Большой) in water or a humid environment.

Generation of combustible gases in water received little research for the fuel of complex composition requiring physical modeling of the damaged spent nuclear fuel to justify fire and explosion safety and obtain experimental dependencies of the combustible gas release for the projected handling conditions with scaling-up and extrapolating the results as appropriate.

The paper presents the results of the experiments conducted at JSC SSC RIAR to investigate the accumulated combustible gases and the calculations made by Sosny R\&D Company regarding the accumulation of radiolytic hydrogen during simulated underwater handling of the leaky AM (AMB) spent fuel dispersed in magnesium and calcium. The findings can be used to justify fire and explosion safety of underwater handling of the damaged AM (AMB) spent fuel, e.g., underwater preparations for radiochemical reprocessing (Kudryavtsev and Smirnov 2010, Smirnov 2010, Kirillov et al. 2012).

\section{Selection and characterization of spent nuclear fuel for experiments}

The composition of the AMB spent fuel varies widely. It contains $1 \%$ to $20 \%$ of ${ }^{235} \mathrm{U}$ and consists of either uranium oxide or uranium-molybdenum alloy in a magnesium matrix $((\mathrm{U}-9 \% \mathrm{Mo})+\mathrm{Mg})$ or uranium carbide in a calcium matrix $(\mathrm{UC}+\mathrm{Ca})$. Taking into account the release of hydrogen and fission products from the spent fuel oxides described in (Gayazov et al. 2018), the experiments used fragments of the irradiated (U-9\% Mo) $+\mathrm{Mg}$ and $\mathrm{UC}+\mathrm{Ca}$ nuclear fuel from the AM reactor, a prototype of the AMB spent fuel.

Three batches of the AM spent fuel rods were selected for the experiment (Table 1).

A visual examination showed that fuel rod No. 2 with the $\mathrm{UC}+\mathrm{Ca}$ matrix was leaky and damaged. All the other fuel rods were most likely leak-tight. The gamma scanning results suggested no fuel leaching from any of the selected fuel rods. Gamma spectrometric examinations of the dissolved spent fuel specimens detected only one radioactive isotope, ${ }^{137} \mathrm{Cs}$ (traces of ${ }^{134} \mathrm{Cs}$ and ${ }^{154} \mathrm{Eu}$ were observed) with the maximum specific activity of $1.08 \cdot 10^{9} \mathrm{~Bq} / \mathrm{g}$ for the (U-9\% Mo) $+\mathrm{Mg}$ spent fuel and $2.7 \cdot 10^{8} \mathrm{~Bq} / \mathrm{g}$ for the $\mathrm{UC}+\mathrm{Ca}$ spent fuel.

The linear density of the fuel rods was determined by measuring the length and weight of the fuel fragments to be $7.1 \pm 0.3 \mathrm{~g} / \mathrm{cm}$ for the $\mathrm{UC}+\mathrm{Ca}$ fuel rods and $9.1 \pm 0.6 \mathrm{~g} /$ $\mathrm{cm}$ for the (U-9\% Mo) $+\mathrm{Mg}$ fuel rods.

\section{Experimental equipment and procedure}

The Material Testing Department, RIAR JSC, used an incell test rig with a process automation system to investigate the behavior of the damaged fuel during simulated handling of the leaky AM (AMB) spent fuel dispersed in magnesium and calcium. The experimental equipment included a model canister, heating, steam pipeline, filtering, condensation, evacuation, gas filling and sampling systems, an EMG-20-6 mass spectrometer, an IRG BDGB-02P detector, and an automated control system (ACS). A more detailed description of the test rig and the measuring equipment is given in (Gayazov et al. 2018).

The SNF specimens as fuel rod fragments were put into a basket inside a cylindrical canister.

With the SNF in water, the experiments monitored pressure, hydrogen and methane concentrations in the free volume of the canister and ${ }^{137} \mathrm{Cs}$ concentration in water after the experiment.

\section{Experimental results and discussion}

\section{Results of experiments with (U-9\% Mo)+Mg fuel rod fragments}

Seven fragments cut from the AM (U-9\% Mo)+Mg fuel rods, each $245 \mathrm{~mm}$ long and with a total mass of $1.565 \mathrm{~kg}$, were put in a leak-tight canister underwater. Before that, the oxide layer was removed from both ends of the fuel

Table 1. Specifications of AM fuel rods under research

\begin{tabular}{|c|c|c|c|c|c|}
\hline Batch (fuel rods) & FA number & Fuel composition & ${ }^{235} \mathrm{U}$ enrichment, \% & Irradiation period & Burnup, MW·day $/ \mathbf{k g U}$ \\
\hline 1 (Nos. 1,2) & AMK-B-16 & $\mathrm{UC}+\mathrm{Ca}$ & 10 & $07.1968-06.1969$ & 6 \\
\hline $2($ Nos. 3,4$)$ & D-62 & $(\mathrm{U}-9 \% \mathrm{Mo})+\mathrm{Mg}$ & 6.5 & 23.01.1979-10.04.1984 & 20 \\
\hline 3 (Nos. 5, 6) & D-45 & $(\mathrm{U}-9 \% \mathrm{Mo})+\mathrm{Mg}$ & 6.5 & $21.09 .1979-10.04 .1984$ & 20 \\
\hline
\end{tabular}




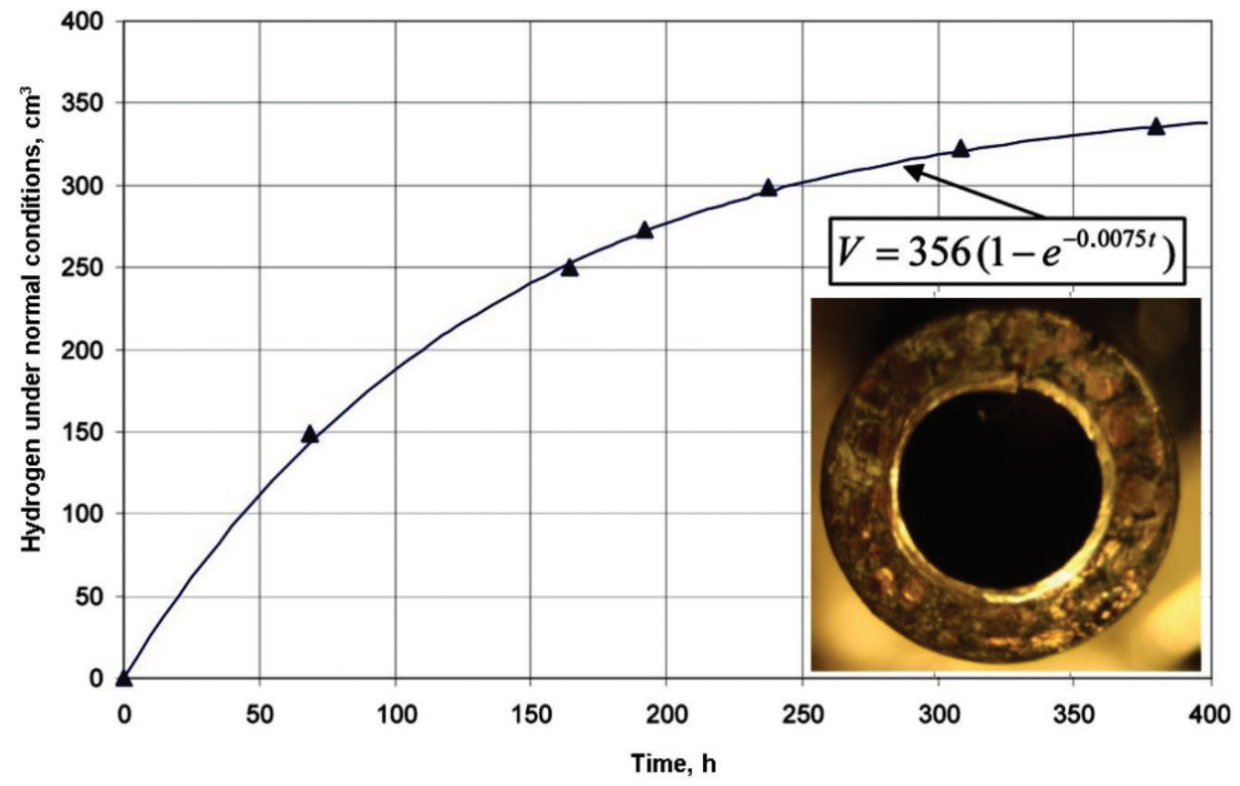

Figure 1. Kinetics of hydrogen accumulation in the free volume of the canister during underwater storage of the $(\mathrm{U}-9 \% \mathrm{Mo})+\mathrm{Mg}$ fuel fragments and a photo of the fragment end.

fragments by cutting off $1 \mathrm{~mm}$. Argon filled up the free volume of the canister at a pressure of 1 bar. The fuel rod fragments remained inside the canister for 380 hours, with the gas samples taken periodically. In 8 days after the soaking started, the water was sampled for the gamma spectrometric analysis that revealed ${ }^{137} \mathrm{Cs}$ with the total activity of $(1.6 \pm 0.2) \times 10^{8} \mathrm{~Bq}$ in 2.91 of the solution.

The characterization of the fuel rods before the experiment determined that the maximum linear activity of ${ }^{137} \mathrm{Cs}$ in the fuel rods was $9.74 \cdot 10^{9} \mathrm{~Bq} / \mathrm{cm}$. According to the findings, the depth of ${ }^{137} \mathrm{Cs}$ leaching on each end of the fragment was $12 \mu \mathrm{m}$ roughly as of the time of sampling.

The gas sample from the canister contained hydrogen only. Fig. 1 demonstrates the kinetics of hydrogen generation approximated best by an exponential function that formally corresponds to the chemical first-order reaction

$$
V=356 \times[1-\exp (-0.0075 t)]
$$

where $V$ is the volume of hydrogen released under normal conditions, $\mathrm{cm}^{3} ; t$ is the time, $\mathrm{h}$.

The contribution of the radiolytic hydrogen released from the SNF canister during the underwater storage was assessed based on the maximum specific activity of ${ }^{137} \mathrm{Cs}$ in the (U-9\%Mo)+Mg fuel.

The accumulation rate for radiolytic hydrogen was calculated by the equation:

$$
v=V_{\mathrm{M}} \times G_{\mathrm{g}} \times D_{\mathrm{Cs}} \times m_{\mathrm{w}} /\left(100 \times N_{\mathrm{A}} \times 1.6 \times 10^{-19} \times 3600\right),
$$

where $v$ is the accumulation rate for radiolytic hydrogen under normal conditions, $1 / \mathrm{s} ; V_{\mathrm{M}}$ is the molar volume of the gas under normal conditions $(22.41 / \mathrm{mol})$; $\mathrm{G} \gamma$ is the radiolytic G-value for molecular hydrogen per $100 \mathrm{eV}$ absorbed (0.45 molecules/100 eV (Kabakchi and Pikayev
1981, Bugayenko et al. 1988)); $\mathrm{D}_{\mathrm{Cs}}$ is ${ }^{137} \mathrm{Cs}$ dose rate, $\mathrm{Gy} / \mathrm{h} ; m_{\mathrm{B}}$ is the mass of water in the canister, $\mathrm{g}$; $\mathrm{N}_{\mathrm{A}}$ is Avogadro's number $\left(6.02 \times 10^{23}\right.$ molecules $\left./ \mathrm{mol}\right)$.

The estimates did not take into account the radiolysis of water due to $\alpha$ - and $\beta$-emissions, since these particles spread only from the thin layer at the fuel ends as thick as the particle path in uranium metal $\left(17.5 \mathrm{mg} / \mathrm{cm}^{2}\right.$ (Available at: ASTAR (NIST 2020a)) or $9 \mu \mathrm{m}$ for $5 \mathrm{MeV} \alpha$-particles with a density of $348 \mathrm{mg} / \mathrm{cm}^{2}$ (Available at: ESTAR (NIST 2020b)) or $183 \mu \mathrm{m}$ for $500 \mathrm{keV} \beta$-particles). The total activity of $\beta$-emitting radionuclides in the AM reactor fuel is one to two orders of magnitude less than that of ${ }^{137} \mathrm{Cs}$; the total activity of $\beta$-emitting radionuclides can be taken equal to that of ${ }^{137} \mathrm{Cs}$.

The absorbed $\gamma$-radiation dose rate was calculated with the MAVRIC functional module (Peplow 2009) of SCALE6.1.2 code package (ORNL/TM-2005/39 2011) developed by Oak Ridge National Laboratory for the U.S. Nuclear Regulatory Commission. The MAVRIC module of the SCALE code package calculates the particle intensity and the dose rate from a source of complex geometry based on Monte Carlo methods.

The absorbed dose rate in the water inside the canister was estimated conservatively for different arrangements of the fuel rod fragments in the canister. One of the fragments was placed along the central axis of the canister, while the others formed a peripheral row being placed symmetrically at the same distance from the axis.

Fig. 2 demonstrates a computational model of the canister containing seven fragments of AM fuel rods.

Fig. 3 presents the calculated absorbed dose rate in the water of the canister as a function of the circle radii for the peripheral fuel rod fragments. It identified the geometry with the maximum dose rate $(12.9 \mathrm{~Gy} / \mathrm{h})$ for the water in the canister. The estimated accumulation rate for radiolytic hydrogen under normal conditions was $1.1 \cdot 10^{-8} \mathrm{l} / \mathrm{s}$. It 


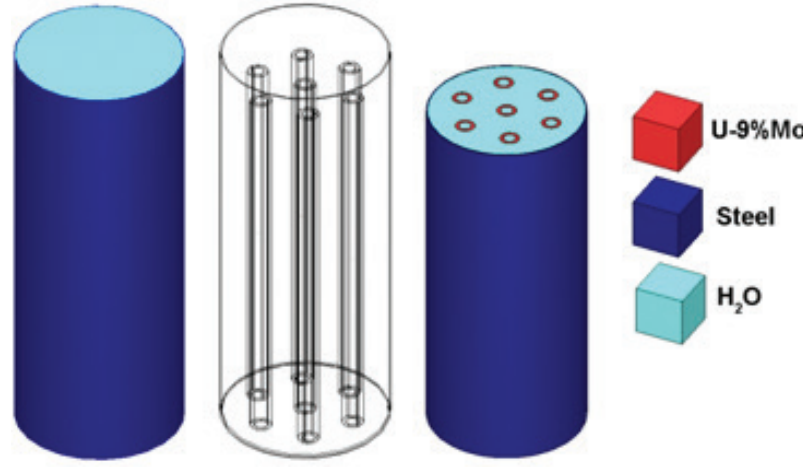

Figure 2. The geometry of Scale 6.1.2 computed model.

corresponds to $15 \mathrm{~cm}^{3}$ of hydrogen accumulated during the experiment, i.e. $4.5 \%$ of the measured value. Thus, it is the electrochemical corrosion of the fuel components that primarily governs the kinetics of hydrogen accumulation during storage of the AM (U-9\%Mo)+Mg spent fuel.

Structurally, the AM reactor fuel rods represent particles of the U-9\%Mo alloy dispersed in the Mg matrix between two cladding tubes made of $06 \mathrm{X} 18 \mathrm{H} 10 \mathrm{~T}$ stainless steel (Fig. 1). It causes galvanic couples between dissimilar metals and intense electrochemical corrosion when the fuel rod is in water. In this system of metals, magnesium $\left(\mathrm{E}_{\mathrm{Mg}+2 / \mathrm{Mg}}=-2.363 \mathrm{~V}\right)$ and uranium $\left(\mathrm{E}_{\mathrm{U}+3 / \mathrm{U}}=-1.789 \mathrm{~V}, \mathrm{E}_{\mathrm{U}-}\right.$ $+4 / \mathrm{U}=-1.5 \mathrm{~V})$ have the most negative standard electrode potentials as compared to molybdenum and stainless steel (Golosov et al. 2013). So, the corrosion processes involve mainly the generation of insoluble hydroxides by the following reactions with hydrogen depolarization:

$$
\begin{gathered}
\mathrm{Mg}+2 \mathrm{H}_{2} \mathrm{O}=\mathrm{Mg}(\mathrm{OH})_{2} \downarrow+\mathrm{H}_{2}, \\
\mathrm{U}+4 \mathrm{H}_{2} \mathrm{O}=\mathrm{UO}_{3} \times \mathrm{H}_{2} \mathrm{O} \downarrow+3 \mathrm{H}_{2}, \\
\mathrm{U}+5 \mathrm{H}_{2} \mathrm{O}=\mathrm{UO}_{2}(\mathrm{OH})_{2} \times \mathrm{H}_{2} \mathrm{O} \downarrow+3 \mathrm{H}_{2}, \\
\mathrm{U}+4 \mathrm{H}_{2} \mathrm{O}=\mathrm{UO}_{2}(\mathrm{OH})_{2} \downarrow+3 \mathrm{H}_{2},
\end{gathered}
$$

The lower hydrogen release observed during the experiment can be an attribute of the insoluble corrosion prod- ucts that impede access to the metal surface for the water, thus gradually decreasing the rate of reactions (3) - (6) until they cease.

Assuming that corrosion on the exposed surface $(\sim 12.6$ $\mathrm{cm}^{2}$ ) induces the hydrogen accumulation, we can conclude that the corrected specific release of hydrogen per unit area of the exposed surface will not exceed $30 \mathrm{ml} / \mathrm{cm}^{2}$ for any period of the underwater storage of the fragmented AM spent fuel with the magnesium matrix. On the assumption that all the hydrogen was generated by reaction (3), the estimated depth of the fuel layer on both ends of the specimen that had reacted with the magnesium matrix was $370 \mu \mathrm{m}$. It is much more than that estimated by the depth of ${ }^{137} \mathrm{Cs}$ leaching from the spent fuel.

Similar laboratory-scale corrosion tests of the AMB $(\mathrm{U}-3 \% \mathrm{Mo})+\mathrm{Mg}$ and $(\mathrm{U}-9 \% \mathrm{Mo})+\mathrm{Mg}$ spent fuel specimens are described in (Golosov et al. 2013). With the (U-9\% Mo) $+\mathrm{Mg}$ specimen stored in a $800 \mathrm{~cm}^{3}$ canister at $+40{ }^{\circ} \mathrm{C}$ for 270 days under a layer of water $\left(60 \mathrm{~cm}^{3}\right)$ in contact with air, the hydrogen release rate did not slow down, and oxygen escaped from the free volume of the canister. The spent fuel specimens were the fuel fragments machined ("coolers") to include both the cladding and the fuel with annular notches on the external cladding and the fuel column to enlarge the total surface of the fuel column (about $40 \mathrm{~cm}^{2}$ ). Rough estimates in paper (Golosov et al. 2013) demonstrate that the amount of hydrogen accumulated per unit area for the fuel stored in canisters underwater for 270 days with air in the free volume of the canisters is an order of magnitude less than for the AM fuel stored in canisters underwater for 16 days with an inert gas in the free volume. It can be due to oxygen depolarization in the presence of oxygen in the air

$$
\begin{gathered}
\mathrm{Mg}+0.5 \mathrm{O}_{2}+\mathrm{H}_{2} \mathrm{O}=\mathrm{Mg}(\mathrm{OH})_{2} \downarrow \\
\mathrm{U}+1.5 \mathrm{O}_{2}+\mathrm{H}_{2} \mathrm{O}=\mathrm{UO}_{3} \times \mathrm{H}_{2} \mathrm{O} \downarrow
\end{gathered}
$$

But the experiment with the fragmented (U-9\% $\mathrm{Mo})+\mathrm{Mg}$ fuel rods from the AM reactor in the absence of oxygen in the free volume of the canister demonstrated an

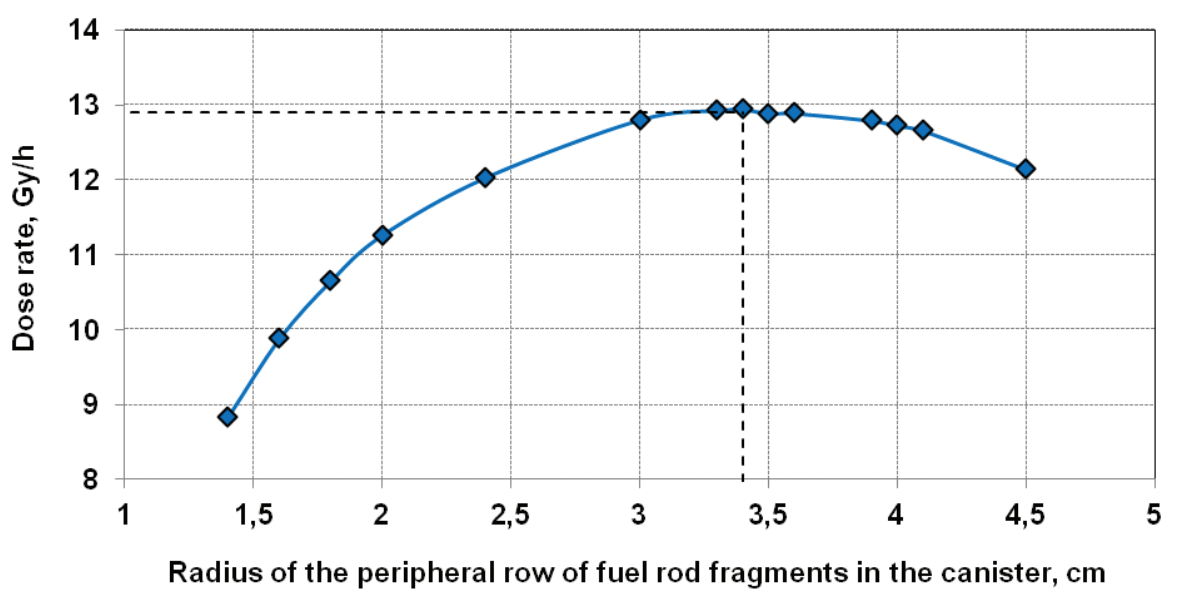

Figure 3. The calculated absorbed dose rate in the water of the canister as a function of the circle radii for the peripheral fuel rod fragments. 


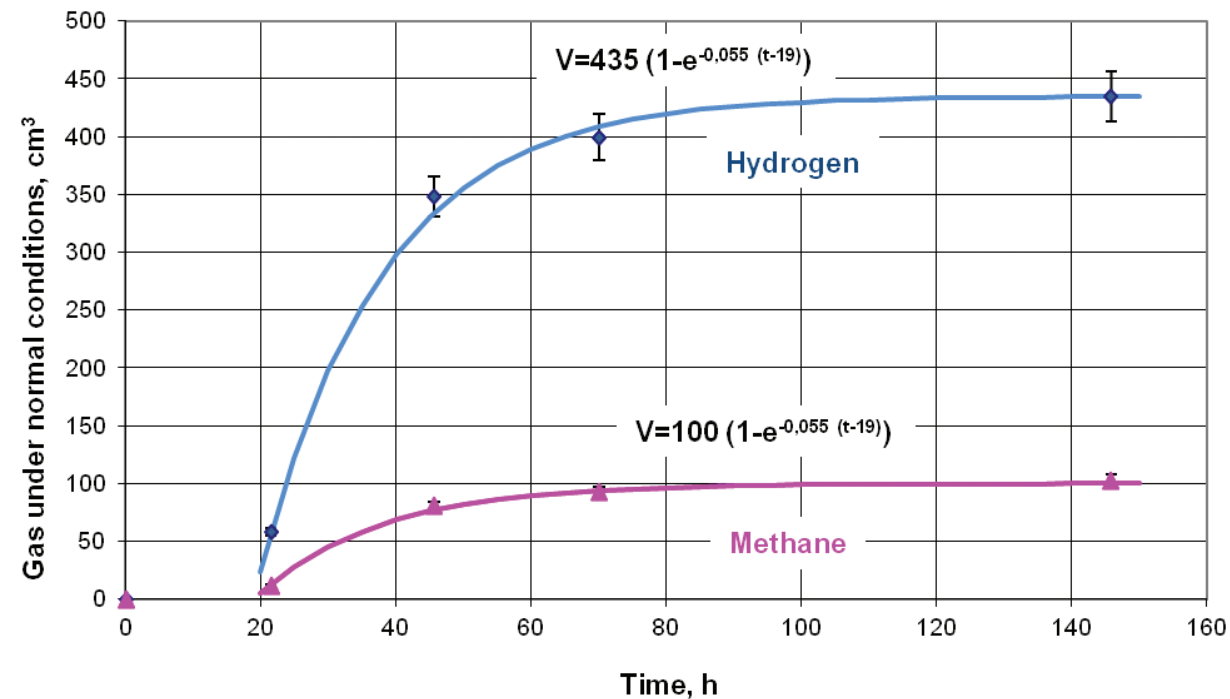

Figure 4. Amounts of hydrogen and methane in the free volume of the canister containing the UC+Ca fuel specimen soaked in water.

evident effect of chemical passivation on the fuel surface during reactions (3) - (6) with hydrogen depolarization due to insoluble corrosion products generated.

\section{Results of experiments with fragmented $\mathrm{UC}+\mathrm{Ca}$ fuel rod}

The experiment used a UC+Ca fuel rod fragment $10 \mathrm{~mm}$ long with a mass of $7.12 \mathrm{~g}$. The canister contained 0.98 1 of water, with 2.61 left for the free volume. The total time of keeping in water was 150 hours. The gas samples contained hydrogen and methane. Fig. 4 presents the kinetics of their release. An incubation period of about 20 hours was followed by an intensive gas release. The gas release rate decreased exponentially over time and nearly stopped in about 100 hours due to the total corrosion of the fuel composition.

During the experiment, the contribution of the radiolytic hydrogen released from the spent fuel canister was assessed based on the maximum specific activity of ${ }^{137} \mathrm{Cs}$ in the $(\mathrm{U}-9 \% \mathrm{Mo})+\mathrm{Mg}$ fuel.

Assuming that the specimen had completely dissolved in the water and the radionuclides were evenly distributed in the solution, the hydrogen accumulation rate was calculated by the equation:

$$
v=\frac{V_{M} \cdot G_{\gamma} \cdot D_{C s} \cdot m_{w}}{100 \cdot N_{A} \cdot 1.6 \cdot 10^{-19} \cdot 3600}+\frac{V_{M} \cdot\left(G_{\alpha} \cdot A_{\alpha} \cdot E_{\alpha}+G_{\beta} \cdot A_{\beta} \cdot E \cdot \beta\right)}{100 \cdot N_{A}},
$$

where $G_{\alpha}$ and $G_{\beta}$ are the radiolytic G-values for molecular hydrogen per $100 \mathrm{eV}$ absorbed $\alpha$ - and $\beta$-emitting energy (1.8 (Allen 1964, Vladimirova 1964) and 0.45 molecules/100 eV, respectively (Kabakchi and Pikayev 1981, Bugayenko et al. 1988)); $A_{\alpha}$ and $A_{\beta}$ are the activities of $\alpha$ - and $\beta$-emitting radionuclides in the water inside the canister, Bq; $E_{\alpha}$ and $E_{\beta}$ are the maximum energies of $\alpha$ - and $\beta$-emitting radionuclides, $\mathrm{keV}$ (5.5 and $0.5 \mathrm{MeV}$, respectively).
The $\gamma$-radiation dose rate was calculated with the MAVRIC functional module of SCALE6.1.2 code package. For $\alpha$ - and $\beta$-emitters, it was assumed that their energy was completely absorbed by the water in the canister. The activity of the $\beta$-emitting radionuclides was taken equal to that of ${ }^{137} \mathrm{Cs}$. The $\alpha$-activity of the specimen was unknown; however, it was conservatively taken equal to half the activity of ${ }^{137} \mathrm{Cs}$ based on the data that the specific $\alpha$-activity of similar AMB spent fuel is $10-50$ times lower than that of ${ }^{137} \mathrm{Cs}$.

The estimated rate of the radiolytic hydrogen release was $3.8 \cdot 10^{-9} \mathrm{l} / \mathrm{s}$. It accumulated only $2 \mathrm{~cm}^{3}$ of hydrogen during the entire experiment, i.e. $5 \%$ of the measured value.

The estimates, as for the Mg-matrix fuel, demonstrated that the hydrogen generation due to the water radiolysis is negligible.

The incubation period may be due to the slow dissolution of the corrosion products (oxides) generated on the fuel end cuts in air.

Based on the fuel assembly specifications sheet and the specimen geometry, uranium carbide and calcium masses were calculated to be $4.63 \mathrm{~g}$ and $0.88 \mathrm{~g}$, respectively. When in contact with water, calcium generates calcium hydroxide and hydrogen as much as $560 \mathrm{~cm}^{3}$ per $1 \mathrm{~g}$ of $\mathrm{Ca}$, while hydrolysis of uranium carbide yields hydrated uranium dioxide, the methane-hydrogen mixture, and a small amount of higher hydrocarbons (Bradley and Ferris 1961, Bradley et al. 1964, Hori and Mukaibo 1967, Peterson and Wymer 1967, Dyck et al. 1975).

Table 2 presents published data on the amount of the gases released per $1 \mathrm{~g}$ of uranium carbide and fractions of methane and hydrogen in the gas during the hydrolysis of irradiated and non-irradiated uranium carbide. The Table also provides the maximum estimated amounts of hydrogen and methane for the completely corroded experimental AM SNF specimen. The maximum possible hydrogen release due to the interaction of calcium with water is $493 \mathrm{ml}$ for the experimental specimen under normal conditions. 
Table 2. Published data on the gases released per $1 \mathrm{~g}$ of non-irradiated $\mathrm{UC}$, fractions of $\mathrm{CH}_{4}$ and $\mathrm{H}_{2}$ in the gas during the UC hydrolysis at $80{ }^{\circ} \mathrm{C}$, the maximum amount of $\mathrm{CH}_{4}$ and $\mathrm{H}_{2}$ for the experimental specimen

\begin{tabular}{|c|c|c|c|c|c|c|c|c|c|c|c|}
\hline Source & $\begin{array}{l}\text { (Bradley et } \\
\text { al. 1964) }\end{array}$ & $\begin{array}{c}\text { (Bradley and } \\
\text { Ferris 1961) }\end{array}$ & $\begin{array}{c}\text { (Hori and } \\
\text { Mukaibo 1967) }\end{array}$ & $\begin{array}{l}\text { (Dyck et } \\
\text { al. 1975) }\end{array}$ & $\begin{array}{l}\text { (Dyck et } \\
\text { al. 1975) }\end{array}$ & $\begin{array}{l}\text { (Dyck et } \\
\text { al. 1975) }\end{array}$ & $\begin{array}{l}\text { (Bradley et } \\
\text { al. 1964) }\end{array}$ & $\begin{array}{l}\text { (Dyck et } \\
\text { al. 1975) }\end{array}$ & $\begin{array}{l}\text { (Dyck et } \\
\text { al. 1975) }\end{array}$ & $\begin{array}{l}\text { (Bradley et } \\
\text { al. 1964) }\end{array}$ & $\begin{array}{l}\text { (Dyck et } \\
\text { al. 1975) }\end{array}$ \\
\hline Temperature, ${ }^{\circ} \mathrm{C}$ & 80 & 80 & 80 & $25-99$ & $25-99$ & 80 & 80 & $25-99$ & $60-80$ & 80 & 99 \\
\hline Burnup, MW·day $/ \mathrm{kgU}$ & 0 & 0 & 0 & 0 & 0 & 0 & 600 & 3375 & 4333 & 6000 & 16667 \\
\hline $\begin{array}{l}\text { Gas amount under normal } \\
\text { conditions, } \mathrm{ml} / \mathrm{gUC}\end{array}$ & 90.4 & 92 & 67.3 & 90.6 & 91.5 & 98.9 & 96.2 & 98.7 & - & - & - \\
\hline $\mathrm{CH}_{4}$ fraction, $\%$ & 88 & 86 & 86 & 82.2 & 87.7 & 76.7 & 67 & 69 & $37-62$ & - & 19.1 \\
\hline $\mathrm{H}_{2}$ fraction, $\%$ & 8.9 & 11 & 11 & 11 & 8.8 & 20.9 & 28 & 25.8 & $33-59$ & - & 77.1 \\
\hline $\begin{array}{l}\text { Estimated amount of } \mathrm{CH}_{4} \\
\text { for AM SNF under normal } \\
\text { conditions, } \mathrm{ml}\end{array}$ & 369 & 367 & 268 & 345 & 372 & 351 & 299 & 315 & - & - & - \\
\hline $\begin{array}{l}\text { Estimated amount of } \mathrm{H}_{2} \\
\text { for AM SNF under normal } \\
\text { conditions, } \mathrm{ml}\end{array}$ & 37 & 47 & 34 & 46 & 37 & 96 & 125 & 118 & - & - & - \\
\hline
\end{tabular}

Although the experiment with the AM spent fuel demonstrated that hydrogen was due to the UC hydrolysis and the calcium-water interaction, the estimates assume that only $25-40 \%$ of uranium carbide and $80-85 \%$ of calcium reacted with water in soaking the experimental UC + Ca fuel specimen.

According to (Bradley et al. 1964) and (Dyck et al. 1975), the higher is the burnup, the lower is the fraction of methane resulting from the UC hydrolysis, and the higher is the fraction of hydrogen. However, with the bunup higher than $4300 \mathrm{MW} \cdot$ day/tU, the specimens become non-reactive to water. Paper (Bradley et al. 1964) states that uranium carbide irradiated up to $6000 \mathrm{MW} \cdot$ day/tU does not undergo hydrolysis (no gas release) at all when kept underwater for 24 hours at least. Paper (Dyck et al. 1975) describes that the gas release was so low and the hydrolysis was so slow for the burnup of $4333 \mathrm{MW} \cdot$ day/ tU and higher that the experiments were stopped before the reaction had ceased, although all the specimens had turned into powder in a short time.

The tested AM fuel specimen had high burnup (about $6270 \mathrm{MW} \cdot$ day/tU), but it witnessed a significant methane release after the incubation period of about 20 hours. This contrasts with the conclusions of papers (Bradley et al. 1964, Dyck et al. 1975) that uranium carbide irradiated up to a high burnup reacts with water poorly.

\section{Conclusions}

Experiments were conducted to study the accumulation of combustible gases during underwater handling simula- tions for the leaky spent nuclear fuel from the AM reactor. The kinetics of hydrogen release for the (U-9\% Mo) $+\mathrm{Mg}$ and $\mathrm{UC}+\mathrm{Ca}$ fuel and the kinetics of methane generation for the carbide spent fuel were obtained. The gas release rate decreases exponentially over time.

The estimates demonstrate that the contribution of radiolytic hydrogen to the gas release is negligible, and the determining source of gases is the chemical interaction between the spent fuel and the water.

It was found that the chemical processes on the surface of the (U-9\% Mo)+Mg fuel nearly cease because of insoluble corrosion products; the depth of the corroded fuel composition on the fuel fragment ends is estimated to be equal to $370 \mu \mathrm{m}$.

As for the carbide SNF, an incubation period of about 20 hours was observed during the experiments followed by an intensive release of hydrogen and methane and complete corrosion of the specimen. The incubation period is presumably due to the oxide layer on the unmachined ends of the fuel fragments. But despite the complete corrosion, the SNF components do not fully interact with water (as little as $25-40 \%$ of uranium carbide and $80-85 \%$ of calcium).

At the same time, the intense release of the gases observed during the experiment disagrees with foreign publications that uranium carbide irradiated up to high burnups reacts with water poorly. The findings can be used to justify fire and explosion safety of underwater handling of the damaged spent nuclear fuel with the considered fuel compositions (the spent fuel from AM, AMB, EGP-6, etc.), e.g., to justify underwater preparations of the AMB spent fuel for reprocessing.

\section{References}

- Allen AO (1964) Radiation Chemistry of Water and Aqueous Solutions. Gosatomizdat Publ., Moscow, 204 pp. [in Russian]

- Bradley MJ, Ferris LM (1961) Processing of Uranium Carbide Reactor Fuels. I. Reaction with Water and HCl. Report ORNL-3101. https://doi.org/10.2172/4006980
Bradley MJ, Goode JH, Ferris LM, Flanary JR, Ullmann JW (1964) Hydrolysis of Neutron-Irradiated Uranium Monocarbide. Inorganic Chemistry 3(3): 454-454. https://doi.org/10.1021/ic50013a033

- Bugayenko LT, Kuzmin MG, Polak LS (1988) High Energy Chemistry. Khimiya Publ., Moscow, 368 pp. [in Russian] 
- Dyck RW, Boase DG, Taylor R, Gerwing AF (1975) A study of the hydrolysis of uranium monocarbide. Part II: Reaction in water between $25^{\circ} \mathrm{C}$ and $99^{\circ} \mathrm{C}$. Whifeshell Nuclear Research Establishment, Pinawa, Manitoba, AECL 4918.

- Gayazov AZ, Komarov SV, Leshchenko AYu, Revenko KYe, Smirnov VP, Zvir YeA, Ilyin PA, Teplov VG (2018) Study of hydrogen generation and radionuclide release during storage of SNF oxides in water. Izvestiya vuzov. Yadernaya Energetika 3: 125-136. https://doi.org/10.26583/npe.2018.3.11 [in Russian]

- Golosov OA, Nikolkin VN, Semerikov VB, Staritsyn SV, Bedin VV (2013) Corrosion of Spent Nuclear Fuel from AMB Reactor. In: Proceedings of the $10^{\text {th }}$ Russian Conference on Reactor Material Science. Dimitrovgrad, 27-31 May 2013. Dimitrovgrad. NIIAR Publ.: 253-288. [in Russian]

- Hori Y, Mukaibo T (1967) Study on the rate and the products of the reaction between uranium monocarbide and water. Journal of Nuclear Science and Technology 4(9): 477-481. https://doi.org/10.1080/1 8811248.1967 .9732790

- Kabakchi SA, Pikayev AK (1981) Methods for calculations of gas release and estimation of explosion hazard of radiochemical water-cooled facilities with biological shielding. Energoizdat Publ., Moscow, 51 pp. [in Russian]

- Kirillov SN, Kolupaev DN, Logunov MV, Ermolin VS, Fedorov YuS, Rodionov SA, Zilberman BYa, Goletskiy ND, Kudinov AS, Shadrin AYu, Smelova TV, Kudryavtsev EG, Haperskaya AV (2012) Possibility of various types of SNF reprocessing at the PA Mayak exampled with AMB SNF. Procedia Chemistry 7: 98-103. https:// doi.org/10.1016/j.proche.2012.10.018

- Kudryavtsev YeG, Smirnov VP (2010) Development of handling techniques for Beloyarsk AMB SNF. Bezopasnost okruzhayushchey sredy 1: 66-68. [in Russian]

- NIST [National Institute of Standards and Technology - Physical Meas. Laboratory] (2020a) The ASTAR program. https://physics.nist. gov/PhysRefData/Star/Text/ASTAR.html [accessed Dec. 10, 2020]

- NIST [National Institute of Standards and Technology - Physical Meas. Laboratory] (2020b) The ESTAR program. https://physics.nist. gov/PhysRefData/Star/Text/ESTAR.html [accessed Dec. 10, 2020]

- ORNL/TM-2005/39 (2011) Scale: a comprehensive modeling and simulation suite for nuclear safety analysis and design, version 6.1, Oak Ridge National Laboratory, Oak Ridge, Tennessee [June].

- Peplow DE (2009) MAVRIC: MONACO with Automatic Variance Reduction Using Importance Calculations. ORNL/TM-2005/39/, I.

- Peterson S, Wymer RG (1967) Chemistry in Nuclear Technology. Atomizdat Publ., Moscow, 430 pp. [in Russian]

- Smirnov VP (2010) Proposals on AMB SNF Management. In: Proceedings of the International Conference on the Management of Spent Fuel from Nuclear Power Reactors. Vienna (Austria), 31 May - 4 Jun. https://www-pub.iaea.org/MTCD/Publications/PDF/SupplementaryMaterials/P1661CD/Session_9.pdf [accessed Dec. 10, 2020]

- Vladimirova MV (1964) Alpha Radiolysis of Water Solutions. Uspekhi khimii 33(4): 462-467. https://doi.org/10.1070/ RC1964v033n04ABEH001397 [in Russian] 